\title{
Contribuição à taxonomia do gênero Aristolochia (Aristolochiaceae) no Estado de Mato Grosso, com uma nova ocorrência para o Brasil
}

\author{
Contribution to the taxonomy of the genus Aristolochia (Aristolochiaceae) in Mato Grosso State, \\ with a new occurrence for Brazil \\ Contribución a la taxonomía del género Aristolochia (Aristolochiaceae) en el Estado de Mato \\ Grosso, con una nueva ocurrencia para Brasil
}

\section{Resumo}

O trabalho apresenta uma chave para identificação das espécies do gênero Aristolochia L. (Aristolochiaceae) do estado de Mato Grosso, Brasil, além de descrições morfológicas para Aristolochia chiquitensis Duch., A. goudotii Duch. e A. hoehneana O.C.Schmidt consideradas novas ocorrências para o estado, sendo A. goudotii uma nova ocorrência também para o Brasil, além de comentários taxonômicos, fitogeográficos e fotografias detalhadas para as três espécies. O trabalho foi realizado entre fevereiro e maio de 2021, com materiais coletados nos municípios de Alta Floresta e Nova Bandeirantes, e análise de espécimes depositados no Herbário da Amazônia Meridional (HERBAM), coletados nos municípios de Colíder, Itaúba e Nova Canã do Norte, extremo norte de Mato Grosso. O estudo morfológico foi realizado no Laboratório de Morfologia Vegetal localizado no HERBAM, da Universidade do Estado de Mato Grosso, Campus de Alta Floresta, fazendo uso de estereomicroscópio e utensílios usuais. A identificação dos táxons, bem como a elaboração da chave dicotômica, foram realizadas por taxonomistas. O presente trabalho amplia de 22 para 25 espécies de Aristolochia em Mato Grosso, bem como, de 83 para 84 espécies no Brasil, demonstrando a importância das expedições de campo, das coleções botânicas, e dos estudos taxonômicos para o conhecimento da biodiversidade.

Palavras-chave: Amazônia; Cipó-milhomem; Flora do Brasil; Morfologia.

\section{Abstract}

The work presents an identification key for the species of the genus Aristolochia L. (Aristolochiaceae) of the state of Mato Grosso, Brazil, as well as morphological descriptions, taxonomic and phytogeographic comments, and detailed photographs of Aristolochia chiquitensis Duch., A. goudotii Duch. and A. hoehneana O.C.Schmidt. These three 
species are new records for the state and A. goudotii is a new record for Brazil. The study was conducted between February and May 2021. Material was collected in the municipalities of Alta Floresta and Nova Bandeirantes and specimens in the Herbário da Amazônia Meridional (HERBAM) were analyzed, collected in the municipalities of Colíder, Itaúba and Nova Canaã do Norte, in northern Mato Grosso. The morphological study was conducted in the Plant Morphology Laboratory in HERBAM at the State University of Mato Grosso, Alta Floresta University Campus, using a stereomicroscope and the usual utensils. The identification of the taxa, as well the elaboration of the dichotomous key, were conducted by taxonomists. The present work increases the number of Aristolochia species from 22 to 25 in Mato Grosso and 83 to 84 in Brazil, demonstrating the importance of field expeditions, botanical collections, and taxonomic studies to our knowledge of biodiversity.

Keywords: Amazon; Cipó-milhomem; Flora of Brazil; Morphology.

\section{Resumen}

El trabajo apresenta una clave para la identificación de las especies del género Aristolochia L. (Aristolochiaceae) del estado de Mato Grosso, Brasil, además de las descripciones morfológicas de Aristolochia chiquitensis Duch., A. goudotii Duch. y A. hoehneana O.C.Schmidt consideradas nuevas ocurrencias para el estado, siendo A. goudotii una nueva ocurrencia también para Brasil, además de comentarios taxonómicos y fitogeográficos y fotografías detalladas de las tres especies. El trabajo se llevó entre febrero y mayo de 2021, con materiales recogidos en los municipios de Alta Floresta y Nova Bandeirantes, y el análisis de especímenes depositados en el Herbário da Amazônia Meridional (HERBAM), recolectados en los municipios de Colíder, Itaúba y Nova Canaã do Norte, en el extremo norte de Mato Grosso. El estudio morfológico se realizó en el Laboratorio de Morfología Vegetal ubicado en HERBAM, de la Universidad del Estado de Mato Grosso, Campus Universitario de Alta Floresta, utilizando estereomicroscopio y utensilios habituales. La identificación de los taxones, así como la elaboración de la clave dicotómica, fueron realizadas por taxonomistas. El presente trabajo amplía de 22 para 25 especies de Aristolochia en Mato Grosso, así como de 83 para 84 especies en el Brasil, demostrando la importancia de las expediciones de campo, colecciones botánicas y estudios taxonómicos para el conocimiento de la biodiversidad.

Palabras clave: Amazonía; Cipó-milhomem; Flora de Brasil; Morfología.

\section{Introdução}

O projeto Flora do Brasil 2020 foi concluído e apresenta para o Estado de Mato Grosso a ocorrência de 6.826 espécies de embriófitas, distribuídas em 1.661 gêneros, destacando-se, as angiospermas, com 6.167 espécies, as samambaias e licófitas, com 340 espécies, as briófitas, com 311 espécies, e com apenas oito espécies, as gimnospermas (Flora do Brasil, 2020).

O estado possui uma área de 903.207,050 km², distribuída em 141 municípios, constituída pelos biomas Amazônia $(53,5 \%)$, Cerrado $(39,7 \%)$ e Pantanal $(6,8 \%)$, no entanto, a perda de biodiversidade ocorre em proporções alarmantes em decorrência da interferência humana no ambiente, principalmente o desmatamento para a produção agropecuária (Borges, et al., 2014). De acordo com o Instituto Nacional de Pesquisas Espaciais (INPE, 2020), entre agosto de 2018 a julho de 2019 , Mato Grosso contribuiu com 16,80\% $\left(1.702 \mathrm{Km}^{2}\right)$ na taxa consolidada de desmatamento entre os nove estados da Amazônia Legal Brasileira. A perda de hábitat é a principal ameaça a flora do Brasil, colocando o Mato Grosso na $11^{\circ}$ posição com 53 espécies ameaçadas de extinção na Lista Vermelha da Flora do Brasil (Martinelli, et al., 2013).

O Mato Grosso, localizado na região Centro-Oeste, está entre os estados com menor esforço de coleta de espécimes de plantas quando se compara com estados das regiões Nordeste, Sudeste e Sul do país (Martinelli, et al., 2013). Visando contribuir no preenchimento das lacunas de coletas botânicas no Norte de Mato Grosso, criou-se, em 2007, o Herbário da Amazônia Meridional (HERBAM) na Universidade do Estado de Mato Grosso, Campus de Alta Floresta (Fernandes, et al., 2015; Lopes, 2015). As coletas realizadas na Amazônia Meridional e depositadas no HERBAM vêm contribuindo de forma significativa para o conhecimento da flora do estado, onde quase 50\% das espécies depositadas no acervo não constam na Lista de Espécies da Flora do Brasil de 2015 (Lopes-Soares, et al., 2013). Só em 2015 foi apresentada uma lista com 38 novas ocorrências de Leguminosae para o estado (Fernandes, et al., 2015). Foi o que aconteceu durante expedições de campo nos municípios de Alta Floresta e Nova Bandeirantes, entre fevereiro e maio de 2021, que permitiram encontrar três espécies do gênero Aristolochia L. (Aristolochiaceae) consideradas novas ocorrências para o estado de Mato Grosso, sendo que uma delas é nova ocorrência para o Brasil. 
O gênero Aristolochia está distribuído nas regiões tropicais e subtropicais do mundo, representado por cerca de 550 espécies (Capellari-Júnior, 2002; González \& Pabón-Mora, 2017), com centros de diversidade na Hispaniola (Haiti e República Dominicana) e no Brasil (González, 2000). As espécies de Aristolochia são caracterizadas por serem trepadeiras, às vezes ervas, subarbustos ou arbustos, habitualmente com raízes ou rizomas espessados; caules geralmente suberificados quando maduros; folhas alternas, simples, frequentemente pecioladas e inteiras, raras vezes 2-7-lobadas, com 3-7 nervuras partindo da base; estípulas ausentes, às vezes com pseudoestípulas amplexicaules; flores axilares, ramifloras ou caulifloras, solitárias ou em inflorescências paucifloras, racemosas ou cimosas, bracteadas ou ebracteadas; perigônio monosimétrico, reto ou curvado, diferenciado em utrículo, tubo e limbo, 1-3-lobado, raras vezes plurilobado ou sem lobos; ginostêmio com 5-6 anteras e 3, 5 ou 6 lóbulos estigmáticos; ovário ínfero, 5-6-carpelar, 5-6-locular; frutos cápsulas, cilíndricas, fusiformes ou subglobosas; sementes numerosas, às vezes aladas, planas ou côncavo-convexas, ovoides, elipsoides, romboides ou triangulares, frequentemente com superfície verrucosa; às vezes com rafe proeminente na face abaxial da semente com um arilo glutinoso (González, 1990).

Na Flora do Brasil 2020, o gênero Aristolochia está representado por 83 espécies, destacando-se, a Floresta Attântica, com 39 espécies, o Cerrado, com 36 espécies, e a Amazônia, com 35 espécies (Freitas, et al., 2020). No Estado de Mato Grosso possui a ocorrência de 22 espécies, 18 no Cerrado, 14 na Amazônia e nenhuma no Pantanal (Freitas, et al., 2020), número bem superior ao apresentado por Dubs (1998) na obra Prodromus Florae Matogrossensis, com 11 espécies.

Dentre os principais autores que realizaram estudos regionais com Aristolochia no Brasil, destaca-se a Flora Fanerogâmica do Estado de São Paulo (Capellari-Júnior, 2002), Flora do Sul do Brasil (Nascimento, 2008), da Mata Atlântica Nordeste (Araújo, 2013), Flora da Bahia (Abreu \& Giullietti, 2016) e Flora do Espírito Santo (Freitas \& Alves-Araújo, 2017).

A importância das espécies do gênero está relacionada principalmente quanto ao uso medicinal e ornamental. Várias espécies são tradicionalmente utilizadas como medicinal no país, como Aristolochia arcuata Mast., A. cymbifera Mart. \& Zucc., A. esperanzae Kuntze, A. gigantea Mart. \& Zucc., A. labiata Willd. e A. triangularis Cham. \& Schltdl. (Lorenzi \& Abreu-Matos, 2008). No Estado de Mato Grosso, algumas espécies de Aristolochia também são citadas como medicinais: Aristolochia labiata, A. odoratissima L., A. silvatica Barb.Rodr. (Araújo, 2017) e A. trilobata L. (Larocca, 2016) são utilizadas na região do município de Alta Floresta; Aristolochia esperanzae é utilizada por moradores rurais no município de Sinop (Barreto \& Spanholi, 2019) e urbanos no município de Juína (Pauli, et al. 2018).

Estudos etnofarmacológicos relatam o uso de espécies de Aristolochia (Aristolochiaceae) como plantas medicinais em várias partes do mundo, no entanto, os ácidos aristolóquicos (AAs) presentes em todas as espécies de Aristolochia, apresentam atividade citogenotóxica e são potentes carcinógenos para roedores e humanos, como nas espécies Aristolochia labiata e Aristolochia triangularis (Souza, et al., 2020). Alegransi et al. (2021) verificaram em estudo do extrato hidroetanólico da espécie Aristolochia triangularis (cipó-mil-homens) quantidade relevante de compostos fenólicos, contudo, não apresentou efeito antioxidante, mas sim um efeito tóxico nas concentrações estudadas, aumentando o dano oxidativo e diminuindo a ação antioxidante.

O potencial ornamental de Aristolochia é amplo de acordo com as espécies de cada região, e mesmo que as flores perderam a corola ao longo da evolução, o cálice se desenvolveu para atuar na atração dos visitantes florais (Pabón-Mora, et al., 2015; Peréz-Mesa, 2019; Suárez-Baron, et al., 2016; 2019; 2021; Muñoz-Gómez, et al., 2021), principalmente o limbo que se tornou a região mais variada e ornamentada podendo ser cultivadas em praças e jardins (Capellari-Júnior, 2005).

Buscando ampliar a lista de espécies da Flora de Mato Grosso, bem como, contribuir com a identificação das espécies de Aristolochia (Aristolochiaceae) no estado, como em investigações farmacológicas, é apresentada uma chave para identificação das espécies do gênero no estado, além de descrições morfológicas para A. chiquitensis Duch., A. goudotii Duch. e A. hoehneana O.C.Schmidt, que são novas ocorrências para o estado, enquanto que a segunda espécie é uma nova ocorrência 
para o Brasil. O trabalho também apresenta comentários taxonômicos e fitogeográficos, fotografias e informações sobre o período de floração e frutificação para as três espécies.

\section{Metodologia}

O trabalho foi realizado entre fevereiro e maio de 2021, a partir de expedições de campo em áreas particulares nos municípios de Alta Floresta e Nova Bandeirantes, além da análise de exsicatas depositadas no Herbário da Amazônia Meridional (HERBAM), da Universidade do Estado de Mato Grosso, Campus de Alta Floresta, provenientes de coletas realizadas nos municípios de Colíder, Itaúba e Nova Canaã do Norte no Estado de Mato Grosso (Figura 1).

Os cinco municípios estão na região geográfica intermediária de Sinop e regiões geográficas imediatas de Alta Floresta e Sinop (IBGE, 2017). A vegetação da região intermediária é bastante diversificada em fisionomias, com a presença de Floresta Ombrófila Densa e Aberta, Floresta Estacional Semidecidual, Floresta Estacional Sempre Verde, Floresta Estacional Decidual, Savana Florestada, Savana Arborizada e Savana Parque, nos domínios fitogeográficos da Amazônia e Cerrado, além de áreas com Tensão Ecológica entre os dois domínios (IBGE, 2012; Borges, et al., 2014). Possui solo com predomínio de Argissolo e Latossolo, com presença de Nitossolo Vermelho, Neossolo Quartzarênico, Neossolo Litólico e Neossolo Plintossolo; predomínio do Clima Equatorial Continental Úmido, com temperatura média entre $23,1^{\circ}$ a $25,7^{\circ} \mathrm{C}$, período seco de maio a setembro e período chuvoso de outubro a abril (SEPLAN, 2017). Destacam na região as pastagens para criação de gado leiteiro e de corte, e monoculturas anuais como soja, algodão e milho, em pequenas e grandes propriedades (Borges, et al., 2014; Mato Grosso, 2015; IBGE, 2017).

As amostras foram coletadas e herborizadas conforme metodologias usuais (Fidalgo \& Bononi, 1989); identificadas por especialista e depositadas no HERBAM. A chave para identificação das espécies com ocorrência no Estado de Mato Grosso foi realizada com base em bibliografia especializada e consulta às descrições originais das espécies (Hoehne, 1927, 1942; González, 1990; Capellari-Júnior, 1991; Nascimento, 2008; Araújo, 2013; Freitas \& Alves-Araújo, 2017; Freitas, et al., 2020).

As descrições morfológicas foram realizadas com base nos materiais coletados e examinados da coleção do HERBAM, com a análise morfológica dos órgãos vegetativos e reprodutivos, frescos, desidratados e/ou reidratados, com auxílio de um estereomicroscópio no Laboratório de Morfologia Vegetal nas dependências do HERBAM.

A terminologia utilizada nas descrições foi baseada em Radford et al. (1974), González (1990) e Barroso et al. (1999); o sistema de classificação está de acordo com o Grupo de Filogenia das Angiospermas (APweb, 2021); as informações fitogeográficas foram baseadas em referências especializadas (IBGE, 2012; Flora do Brasil, 2020); e, o mapa, foi elaborado utilizando-se o software ArcGIS $^{\circledR}$ 10.2.2, licença teste, com uso dos recursos do ArcMap para elaboração do mapa como as bases cartográficas do Sistema Geodésico Mundial 1984 (WGS-84) e o sistema de projeção Universal Transversa de Mercator (UTM). 
Figura 1. Municípios no extremo Norte de Mato Grosso com coletas de Aristolochia chiquitensis Duch., Aristolochia goudotii Ann. e Aristolochia hoehneana O.C.Schmidt.

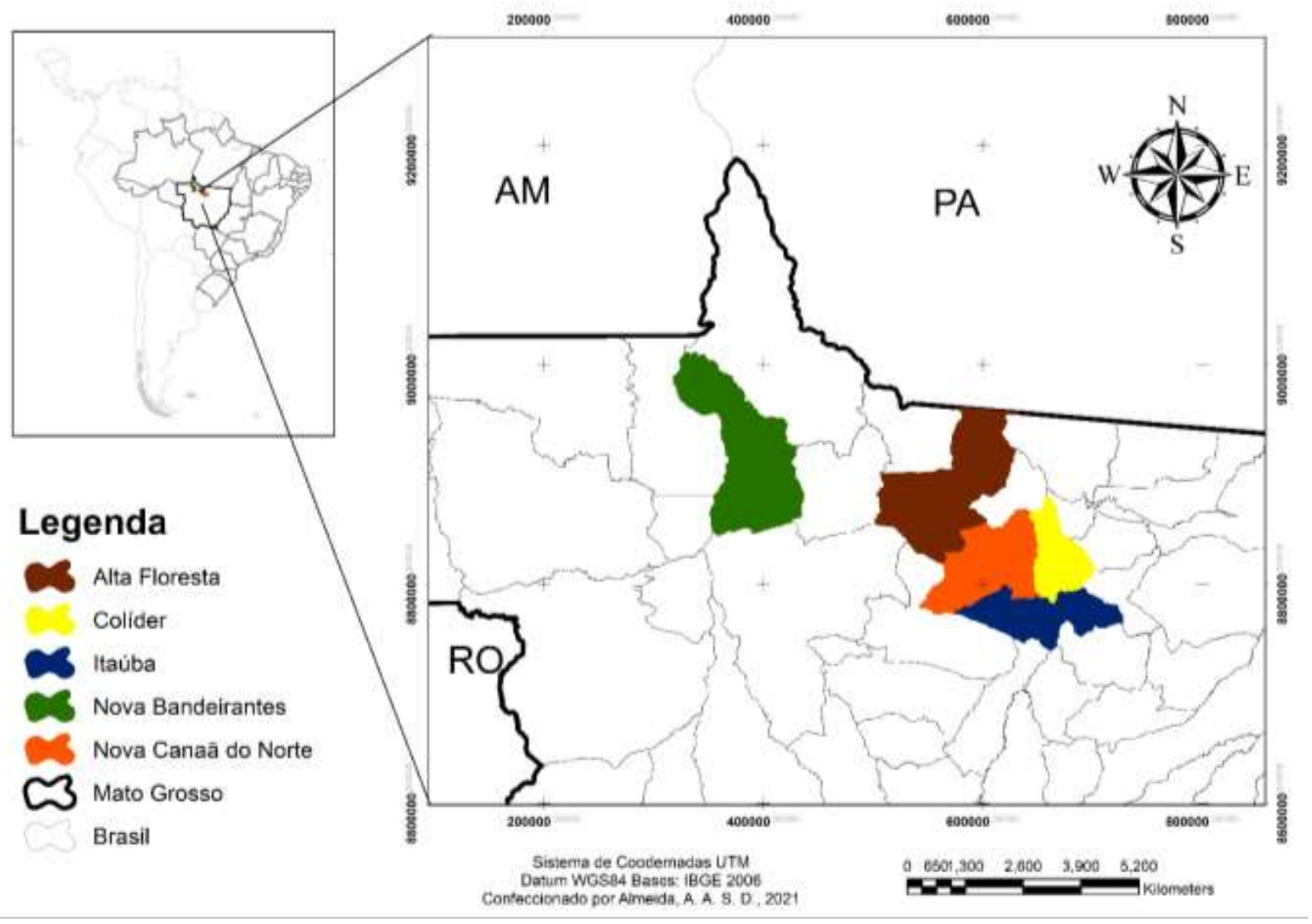

Fonte: Autores.

\section{Resultados e Discussão}

O trabalho apresenta para a flora do Estado de Mato Grosso a ocorrência de 25 espécies do gênero Aristolochia, facilmente reconhecidas na chave de identificação apresentada a seguir. As espécies A. chiquitensis Duch., A. goudotii Duch. e A. hoehneana O. C. Schmidt são novas ocorrências para o estado, sendo a segunda espécie uma nova ocorrência também para o Brasil, passando de 83 para 84 espécies.

\section{Chave de identificação das espécies de Aristolochia no Estado de Mato Grosso}

1. Pseudoestípulas presentes 2

2. Limbo floral unilabiado

3. Limbo com base não peltada; folha com base truncada. Aristolochia triangularis Cham. \& Schltdl.

3'. Limbo com base peltada; folha com base cordada 4

4. Folhas hastadas. Limbo do perianto rosado à púrpureo, com mancha amarela na entrada do tubo. Cápsula estreito-cilíndrica, 4.5-8 × 1-2 cm, rostro sem anel subapical; sementes 3-3.5 × 2-2.5 mm, não aladas, e com arilo glutinoso Aristolochia odoratissima $\mathbf{L}$. 
4'. Folhas ovais a largamente ovais. Limbo do perianto púrpureo com veias brancas, com mancha purpúrea na entrada do tubo. Cápsula largo-cilíndrica, 5-6 × 2-3 cm, rostro com anel subapical; sementes 4-6 ×3$5 \mathrm{~mm}$, com uma ala periférica, e sem arilo glutinoso Aristolochia elegans Mast.

2'. Limbo floral bilobado.

5. Limbo floral bilobado (com dois lobos laterais)

Aristolochia ridicula N.E.Brown

5'. Limbo floral bilabiado (com lábio superior e inferior) 6

6. Ápice do limbo superior cuspidado

7. Limbo superior e inferior de mesmo tamanho

Aristolochia gibertii Hook.

7'. Limbo superior maior do que o inferior Aristolochia esperanzae Kuntze

6'. Ápice do limbo superior não cuspidado

8. Limbo superior oblongo Aristolochia gehrtii Hoehne

8'. Limbo superior espatulado Aristolochia warmingii Mast.

1'. Pseudoestípulas ausentes

9. Inflorescências unifloras ou com racemos/ramos floríferos axilares com entrenós das flores $>5 \mathrm{~mm}$...................... 10

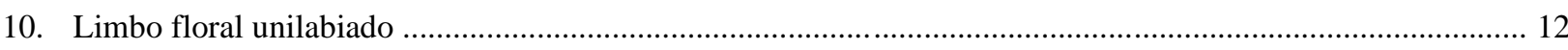

11. Limbo com fímbrias

12. Ramos e pecíolos glabros Aristolochia arcuata Mast.

12'. Ramos e pecíolos glabrescentes, puberulentos ou pilosos 13

13. Pecíolo hirsuto Aristolochia pilosa Kunth

13'. Pecíolo glabrescente ou puberulento 14

14. Base do limbo constricta Aristolochia chiquitensis Duch.

14'. Base do limbo não constricta Aristolochia rugosa Lam.

11’. Limbo sem fímbrias 15

15. Ervas 16

16. Inflorescências usualmente em ramos floríferos Aristolochia holostylis F.González 16'. Inflorescências unifloras Aristolochia claussenii Duch.

15'. Trepadeiras

17. Face adaxial das folhas desprovida de tricomas ...... Aristolochia cordigera Willd. ex Klotzsch

17'. Face adaxial das folhas provida de tricomas 18

18. Perianto glabro; utrículo não diferenciado do tubo ..... Aristolochia stomachoidis Hoehne

18'. Perianto hirsuto; utrículo diferenciado do tubo Aristolochia urupaensis Hoehne

10'. Limbo floral bi- ou trilabiado 19

19. Limbo trilabiado; lábio superior não caudado Aristolochia trilabiata Glaz.

19’. Limbo bilabiado; lábio superior caudado Aristolochia weddellii Duch.

9'. Inflorescências em racemos caulifloros com entrenós das flores $<5 \mathrm{~mm}$ e zona basal de abscisão ausente ou inflorescências em tirsos/ripídios axilares ou caulifloros e zona basal de abscisão presente nas flores e folhas) ...... 20

20. Inflorescências em tirsos/ripídios axilares ou caulifloros; zona basal de abscisão presente nas flores e folhas

21. Limbo floral bilabiado (com um lábio superior e um inferior) Aristolochia hoehneana O.C.Schmidt

21'. Limbo floral unilabiado 22

22. Lâmina com face adaxial glabrescente Aristolochia acutifolia Duch. 
22'. Lâmina com face adaxial glabra

23. Lâmina com base assimétrica Aristolochia silvatica Barb.Rodr. 23'. Lâmina com base simétrica Aristolochia melastoma Silva Manso ex Duch.

20'. Inflorescências em racemos caulifloros com entrenós das flores $<5 \mathrm{~mm}$; zona basal de abscisão ausente nas flores e folhas 24

24. Tubo floral $0,6-1 \mathrm{~cm}$ compr. Siringe presente, inequilátera Aristolochia ruiziana Duch.

24'. Tubo floral 1,6-3 cm compr. Siringe ausente Aristolochia goudotii Duch.

3.1. Aristolochia chiquitensis Duch., Ann. Sci. Nat., Bot., sér. 4, 2: 49-50. 1854.

Figura 2

Trepadeiras. Caule não suberoso; ramos jovens cilíndricos, entrenós 6,5-17 cm compr., glabrescentes. Pseudoestípulas ausentes. Pecíolo 1,5-3,5 cm, glabrescente a puberulento; lâmina 3-12 × 2,5-12 cm, ovada a amplamente ovada, cartácea, base cordada a sagitada, sinus $1-4 \mathrm{~cm}$ de profundidade, ápice agudo, raramente obtuso, face adaxial glabra, face abaxial densamente puberulenta, pontuações presentes, veias primárias basais 3(5), impressas na face adaxial e proeminentes na face abaxial. Inflorescências unifloras, axilares. Pedúnculo + ovário 2,8-4,7 cm compr., rostro $0,7-1,8$ mm compr., puberulento. Perianto esverdeado com máculas vináceas, externamente puberulento; utrículo 1,5-1,8 × 1,1-1,3 $\mathrm{cm}$, obovoide; siringe 0,8-1,1 mm compr., inequilátera, internamente com tricomas longos, delgados na base com ápices direcionados ao utrículo; tubo 2,4-3 × 0,3-0,6 (proximal) - 0,7-1,6 (distal) $\mathrm{cm}$, infundibuliforme, reto a levemente arqueado, ângulo $140-180^{\circ} \mathrm{em}$ relação ao utrículo, limbo 1,5-1,7 × 1-1,3 cm, ovado, constricto na base, ápice obtuso, ângulo 140-180 em relação ao utrículo, externamente pubescente, esverdeado, internamente com mácula transversal na base, enegrecida, 2/3 distal com fímbrias enegrecidas a enegrecido-esbranquiçadas, 0,5-4 mm compr. Ginostêmio 4,8-6,5 mm compr., anteras 3-5 mm de compr., estípite 0,5-2 mm compr. Cápsula 3-6 × 1-1,3 cm, estreitamente elíptica, pubescente, base aguda, ápice agudo, rostro 3-5 mm compr., veia média de cada carpelo proeminente, 0,9-1 mm; semente não observada.

Material examinado. Brasil. Mato Grosso. Alta Floresta, Setor E, rua 5, número 521, 21/V/2021, fl., J. M. Fernandes \& C. R. A. S. Lopes 1774 (HERBAM), Setor Santa Maria, próximo à Zootecnia Sal Gado, 22/V/2021, fl., fr., J. M. Fernandes 1775 (HERBAM), 22/V/2021, fl., fr., J. M. Fernandes 1776 (HERBAM). Colíder, resgate de flora da UHE Colíder, estrada de acesso ao Lote B e G, 30/III/2015, fl., fr., M. E. Engels \& T. Cardoso da Silva 3442 (HERBAM). Itaúba, resgate de flora da UHE Colíder, CT3, 05/XII/2015, fl., M. E. Engels 3911 (HERBAM), Lote G de supressão, 03/II/2015, fl., M. E. Engels \& A. Z. Bronholi 3079 (HERBAM), Lote G de supressão, 27/V/2015, fr., M. E. Engels et al. 3469 (HERBAM), CT3, 03/XI/2014, fl., fr., M. E. Engels et al. 3469 (HERBAM). Nova Canaã do Norte, resgate de flora da UHE Colíder, CT1, canteiro de obras, 21/XI/2014, fl., M. E. Engels 3215 (HERBAM).

Aristolochia chiquitensis pertence à Aristolochia sér. Hexandrae subsér. Hexandrae F. González, devido a presença de inflorescências unifloras não subtendidas por brácteas (González, 1990; 1991). Dentre as espécies brasileiras, é morfologicamente similar a A. arcuata Mast., mas difere desta pela base do limbo constricta e ramos glabrescentes (vs. base do limbo não constricta e ramos glabros em A. arcuata) (Freitas, et al., 2020). 
Research, Society and Development, v. 10, n. 10, e518101018676, 2021

(CC BY 4.0) | ISSN 2525-3409 | DOI: http://dx.doi.org/10.33448/rsd-v10i10.18676

Figura 2. Aristolochia chiquitensis: A, hábito; B, folha, face adaxial; C-D, flores; E, parte apical do ovário com rostro (seta) e parte basal do utrículo com pontoações enegrecidas; F, corte longitudinal no utrículo mostrando ginostêmio (seta 1), osmóforos (seta 2) e siringe (seta 3); G, fruto com rostro no ápice (seta).
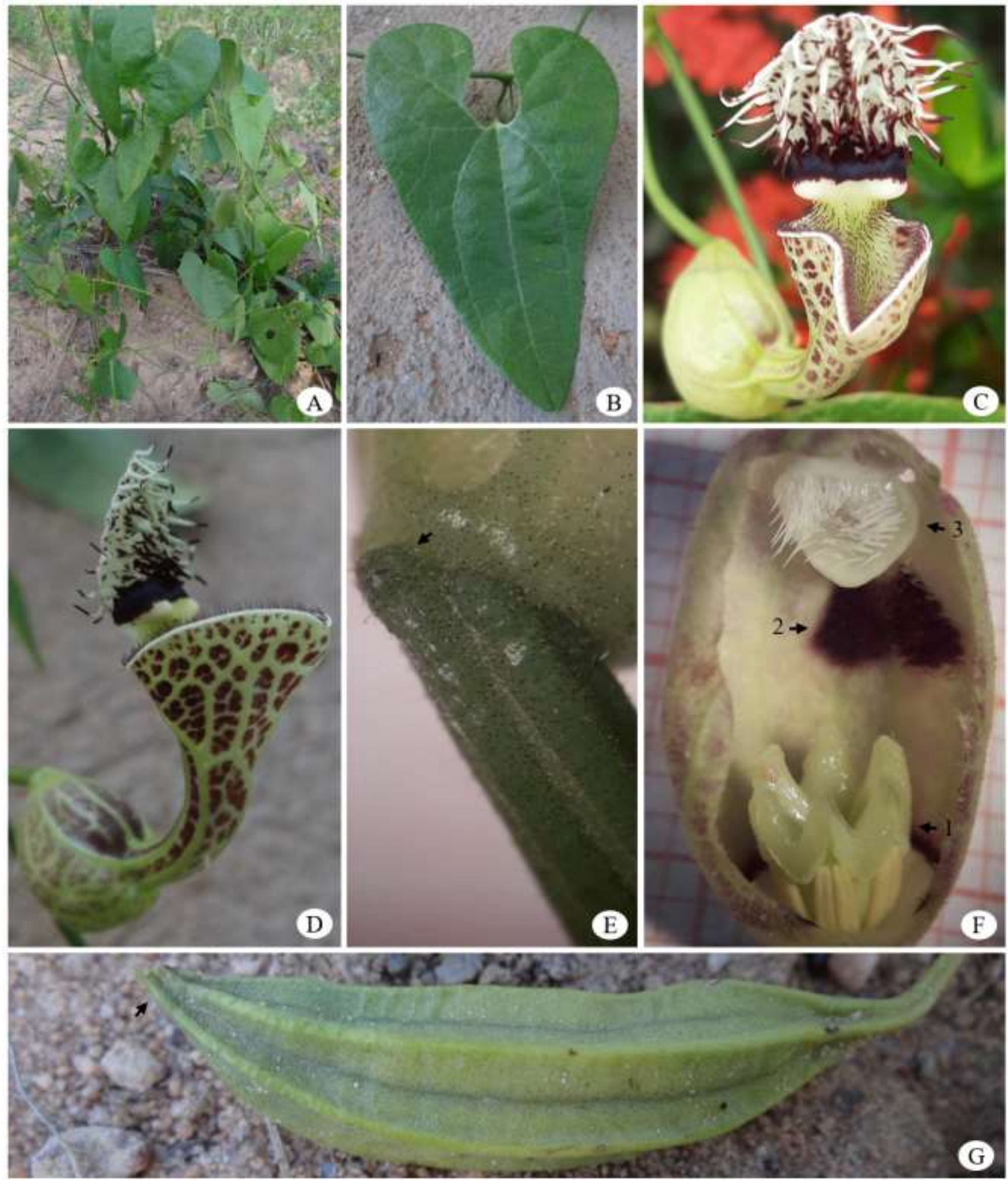

Fonte: J. M. Fernandes (A, B, D-G), C. R. A. Soares-Lopes (C).

Aristolochia chiquitensis ocorre na Bolívia e Brasil (Ulloa-Ulloa, et al., 2017), sendo no Brasil registrada nos estados do Alagoas, Amazonas, Bahia, Ceará, Maranhão, Minas Gerais, Pará, Paraíba, Pernambuco, Piauí e Rio de Janeiro, na 
Amazônia, Cerrado e Mata Atlântica (BFG, 2015). No presente trabalho amplia a sua distribuição geográfica para o Estado de Mato Grosso, nos municípios de Alta Floresta, Colíder, Itaúba e Nova Canaã do Norte. Foi coletada em floresta de galeria, área antrópica e região de ecótono com mosaico de floresta estacional semidecidual, floresta estacional decidual e savana entre a Floresta Amazônica e Cerrado, sob domínio da Amazônia.

As populações amostradas em Alta Floresta possuem indivíduos com até $1,2 \mathrm{~m}$ de comprimento, consideradas trepadeiras volúveis e bastante delicadas. Foi coletada com flor entre os meses de novembro e maio e com fruto também entre novembro e maio.

\subsection{Aristolochia goudotii Duch., Ann. Sci. Nat., Bot., ser. 4, 2: 66-68 1854.}

Figura 3

Lianas. Caule suberoso; ramos jovens cilíndricos a subcilíndricos, entrenós 7-16 cm compr., sulcados, glabros. Pseudoestípulas ausentes. Pecíolo 3-7 cm compr., glabrescente; lâmina 5-16,8 × 4,5-15,5 cm, amplamente ovada, membranácea, base cordada, raramente subcordada, sinus 1,2-10 mm de profundidade, levemente peltada, ápice acuminado, face adaxial glabra, face abaxial curto-vilosa, glauca, veias primárias basais 5(7). Inflorescências em racemos caulifloros, pedúnculo 1-2 mm compr., raque 6-8 mm compr., entrenós 1-3 mm compr., brácteas 1,8-2,2 × 1,7-2,2 mm, ovadas a amplamente ovadas. Pedicelo + ovário 3-5,5 cm de compr., sulcado, glabrescente. Perianto bege com estrias vináceas, externamente glabro; utrículo obovóide, 1,6-2,9 × 1,2-1,5 cm, internamente com tricomas esparsos; siringe ausente; tubo 1,6$2,7 \mathrm{~cm}$ compr. $\times$ 0,5-0,6 cm (proximal) $-0,7-1,1 \mathrm{~cm}$ (distal) diâm., infundibuliforme, internamente com tricomas longos, esparsos; limbo unilabiado, amplamente ovado, 2,4-4,5 × 3-4,4 cm, com manchas vináceas e tricomas esbranquiçados internamente, efimbriado, papilas ausentes, base obtusa, peltada, ápice obtuso com acúmen presente, 0,8-1 mm compr. Ginostêmio 4-5 mm compr., anteras 2-2,5 mm compr., estípite 1-2 mm compr. Cápsula 4,5-6,8 × 1,2-1,3 cm, estreitamente cilíndrica, pubescente, base atenuada, ápice agudo, rostro 1-2 mm compr., veia média de cada carpelo proeminente, $1 \mathrm{~mm}$; semente 5,5-6,4 × 2,4-2,6 mm, elíptica, côncavo-convexa, não verrucosa, rafe levemente proeminente.

Material examinado. Brasil. Mato Grosso. Nova Bandeirantes, Sitio do Valdo, 06/III/2021, fl., fr., D. F. Silva 196 (HERBAM).

Aristolochia goudotii pertence à Aristolochia sér. Hexandrae subsér. Anthocaulicae F. González, devido a presença de inflorescências em racemos ramifloros ou caulifloros, com entrenós entre as flores reduzidos $(<5 \mathrm{~mm})$ e flores subtendidas por pequenas brácteas (González, 1990; 1991). Dentre as espécies brasileiras, é morfologicamente similar a A. ruiziana Duch., mas difere desta pelo tubo floral com 16-30 mm compr. e siringe ausente (vs. tubo com 6-10 mm compr. e siringe presente e inequilátera em A. ruiziana) (Freitas, et al., 2020).

É nativa na Colômbia, em floresta tropical (González, 1990; Ulloa-Ulloa, et al., 2017). Sua distribuição geográfica é ampliada ao Brasil, com o primeiro registro de coleta no município de Nova Bandeirantes, Estado de Mato Grosso, região Centro-Oeste do país. A espécie foi coletada em um fragmento de floresta ombrófila densa e aberta. As flores estavam aproximadamente a $50 \mathrm{~cm}$ do solo. A área que a espécie foi coletada consiste em um fragmento que vem constantemente sofrendo com o desmatamento e queimada para o plantio de cana-de-açúcar, o que coloca o táxon em risco. Foi coletada com flores e frutos em março. 
Research, Society and Development, v. 10, n. 10, e518101018676, 2021

(CC BY 4.0) | ISSN 2525-3409 | DOI: http://dx.doi.org/10.33448/rsd-v10i10.18676

Figura 3. Aristolochia goudotii: A, caule suberoso; B, Folha, face adaxial (seta indica a base levemente peltada); C, Folha, face abaxial; D, inflorescências em racemos curtos, caulifloros; E, flor em visão frontal; F, ginostêmio (seta 1) com estípite (seta 2); G, fruto com rostro no ápice (seta); H, sementes com visão da rafe (seta).
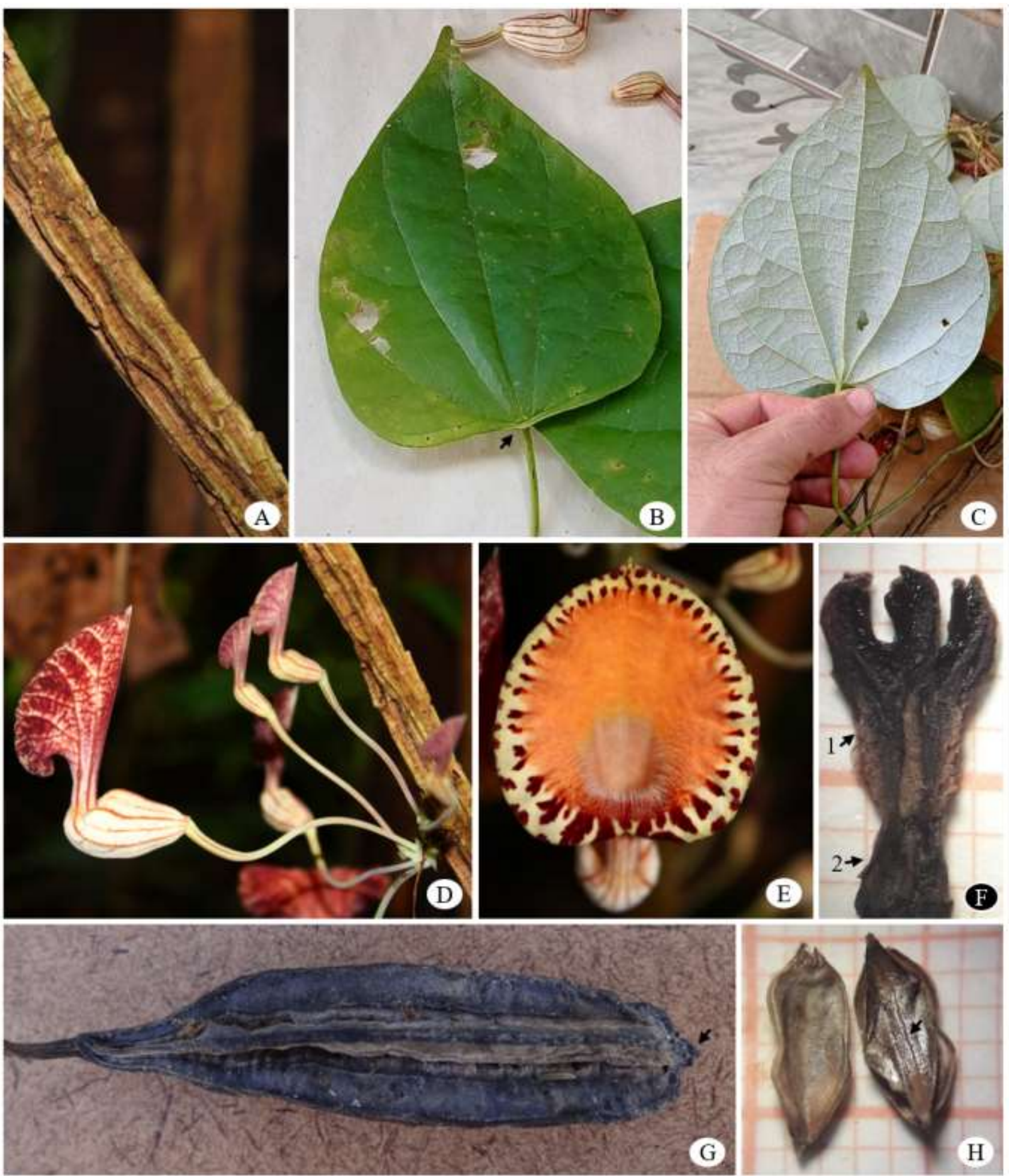

Fonte: D. F. Silva (A-E), J. M. Fernandes (F-H). 
3.3. Aristolochia hoehneana O.C.Schmidt, Notizbl. Bot. Gart. Berlin-Dahlem 12: 390. 1935.

Figura 4

Lianas. Caule suberoso; ramos jovens cilíndricos, entrenós 4-13 cm compr., densamente hirsutos. Pseudoestípulas ausentes. Pecíolo 4-6,5 cm compr., densamente hirsuto, com zona basal de abscisão; lâmina 8,5-23 × 4,5-15,5 cm, ovada, geralmente com região mediana levemente constrita, cartácea, base fortemente cordada, sinus 10-25 mm de profundidade, ápice agudo a acuminado, face adaxial hirsuta, brilhosa, áspera, nervuras não proeminentes, face abaxial densamente hirsuta, nervuras proeminentes, venação primária basal 5. Inflorescências em ripídios axilares, pedúnculo 7-13 mm compr., raque 1,26,5 cm compr., densamente hirsuta, entrenós 5-7 mm compr., até 13 flores, cada flor oposta a uma bráctea deltóide 2-3,5 $\times 1-$ 1,6 mm, hirsutas a seríceas. Pedicelo + ovário 23-27 mm compr., linear, densamente hirsuto a seríceo, com zona basal de abscisão. Perianto vináceo com estrias esverdeadas proeminentes, externamente puberulento; utrículo amplamente obovado, 2,7-3,4 × 1,5-2 cm, curto-lanoso; siringe 1,5-2 mm compr., equilátera, tricomas longos ausentes; tubo 2,8-3,5 cm compr. $\times$ 0,4-0,5 cm diâm. (proximal) - 1,4-1,7 cm diâm. (distal), infundibuliforme, curvado, glabro; limbo bilabiado, com um lábio superior e um inferior, lábios subiguais, curvos para o centro, vináceo com estrias esverdeadas; lábio superior lanceolado, 44,8 × 1-1,2 cm, fímbrias ausentes, margem inteira, ápice revoluto com cavidades internamente; lábio inferior 1,8-2,5 × 1,2-1,6 $\mathrm{cm}$, margem inteira, ápice curtamente retuso a arredondado. Ginostêmio 6,5-8 mm compr., anteras 2,8-3 mm compr., estípite $1 \mathrm{~mm}$ compr. Cápsula 10-11,5 × 3,7-4,5 cm, oblonga, puberulenta, base atenuada, ápice truncado, rostro ausente, septos em treliça, veia média de cada carpelo proeminente, $2 \mathrm{~mm}$; sementes 7,5-10 × 8-15 mm, amplamente obovóides, plana, verrucosa, bialadas, rafe presente, proeminente.

Material examinado. Brasil. Mato Grosso. Alta Floresta, Comunidade Guadalupe, propriedade do Sr. Salvador, 11/II/2021, fl., J. M. Fernandes 1757 (HERBAM), rancho do Aguinaldo, 11/II/2021, fr., J. M. Fernandes 1758 (HERBAM); Comunidade São Bento, $1^{a}$ Sul, Chácara do Denis, 21/III/2021, fr., J. M. Fernandes 1759 (HERBAM), Chácara do Zeca, 21/III/2021, fl., fr., J. M. Fernandes 1760 (HERBAM), 21/III/2021, fl., fr., J. M. Fernandes 1760 (HERBAM), 21/III/2021, fl., fr., J. M. Fernandes 1761 (HERBAM), Parque Zoobotânico Leopoldo Linhares Fernandes, 26/V/2009, fl., fr., F. F. Cabral 71 (HERBAM).

Aristolochia hoehneana pertence à Aristolochia sér. Thyrsicae F. González, que tem como característica a presença de sinflorescências tirsóides, pecíolos e pedúnculos com zona basal de abscisão, fruto com septo serreado e sementes bialadas (González 1990; 1991). Dentre as espécies desta série no Brasil, é morfologicamente similar a A. sprucei Mast., mas difere desta pelas folhas com face adaxial híspido pubérula e limbo bilabiado (vs. folhas com face adaxial glabrescente e limbo unilabiado em A. sprucei) (Freitas, et al., 2020).

A espécie é restrita a Bolívia e Brasil (Ulloa-Ulloa, et al., 2017). No Brasil, tem registro de coleta no Estado do Acre, Norte do país, em disjunções de Cerrado lato sensu sob domínio da Amazônia (Freitas, et al., 2020). O presente trabalho apresenta o primeiro registro da espécie para o Centro-Oeste do Brasil, com coletas no município de Alta Floresta, Mato Grosso. Essa espécie ocorre em floresta ombrófila aberta, floresta estacional semidecidual, mata ciliar e em área antrópica. Foi coletada com flores entre novembro e maio e com frutos entre fevereiro e maio. 
Research, Society and Development, v. 10, n. 10, e518101018676, 2021

(CC BY 4.0) | ISSN 2525-3409 | DOI: http://dx.doi.org/10.33448/rsd-v10i10.18676

Figura 4. Aristolochia hoehneana: A, caule suberoso; B, indumento de ramo jovem; C, folha, face adaxial; D, flor, vista lateral; E, ápice do lábio superior do limbo com cavidades; F, corte longitudinal no utrículo mostrando ginostêmio (seta 1) e siringe (seta 2); G, ginostêmio estipitado; H, cápsula antes da deiscência; I, semente; J, semente com visão da rafe (seta).
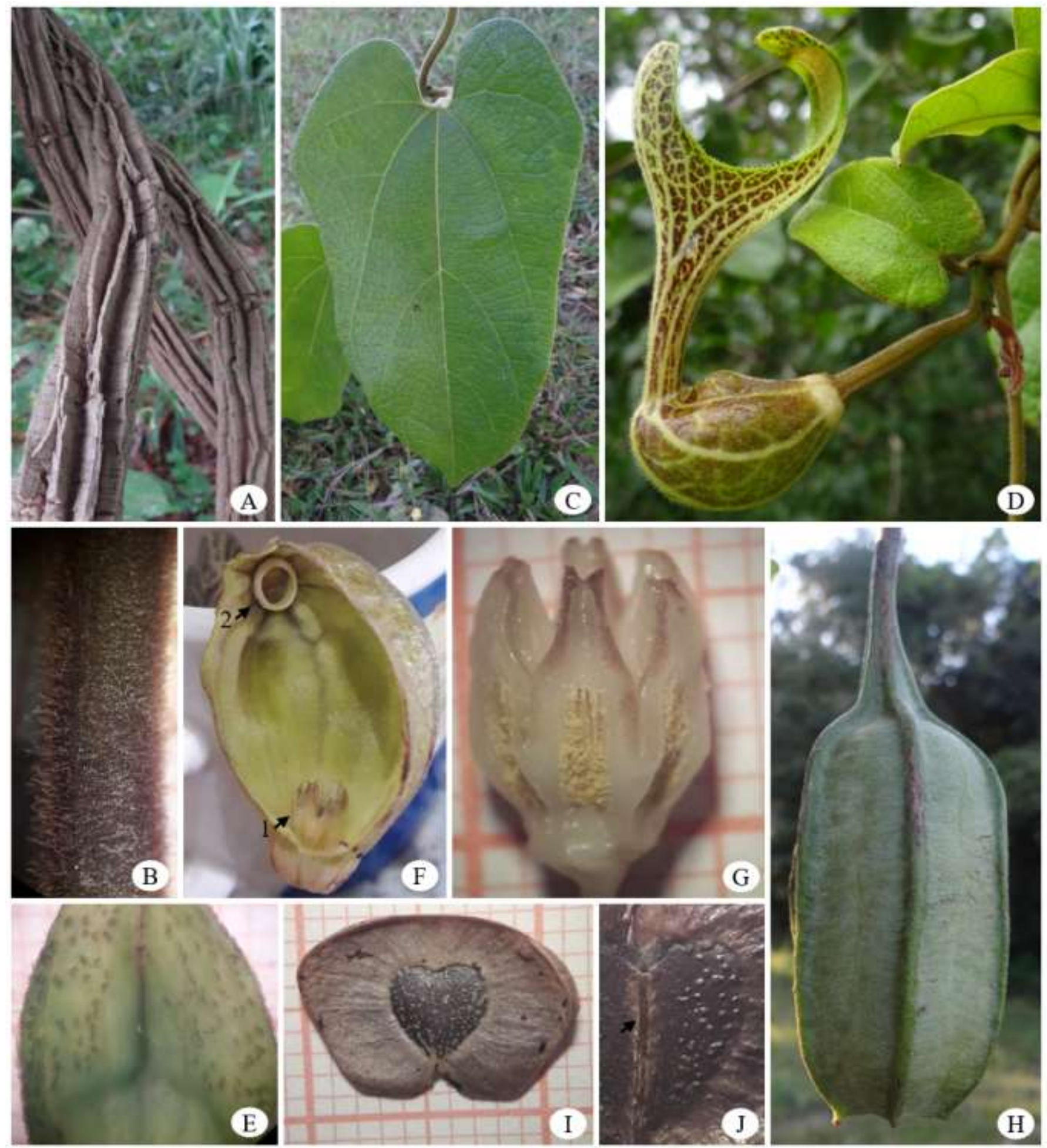

Fonte: J. M. Fernandes (A-J).

\section{Conclusão}

O trabalho amplia a distribuição geográfica das espécies Aristolochia chiquitensis, A. goudotii e A. hoehneana para o Estado de Mato Grosso, e da segunda espécie para o Brasil. 
Fica evidente a importância dos fragmentos florestais como fonte de novas ocorrências de angiospermas, tonando-se locais cruciais para a conservação de espécies nativas, potencializando o melhor conhecimento das estruturas morfológicas, como de Aristolochia. Maiores esforços de coleta nessas áreas também são necessários, bem como coletas sistematizadas.

Com uma lista florística atualizada, como de Aristolochia em Mato Grosso, facilita as investigações científicas em outras áreas da ciência, por exemplo, em estudos de relações planta-animal e fitoquímicos de espécies utilizadas na medicina popular.

\section{Referências}

Abreu, I. S. \& Giullietti, A. M. (2016). Flora da Bahia: Aristolochiaceae. Sitientibus série Ciências Biológicas, 16, 10.13102/scb1059. 10.13102/scb1059.

Alegransi, C., Cunha, A., Heringer, T. A., Vincensi, T. M., Dias, T. O., Goulart, J. S., Ribeiro, G. M., Rodrigues, E. E. C. \& Cattaneo, R. (2021). Avaliação do efeito antioxidante de cipó-mil-homens (Aristolochia triangularis Cham.) em eritrócitos de pacientes com doenças neurodegenerativas. Research, Society and Development, 10 (5), e58710514903. Doi.org/10.33448/rsd-v10i5.14903

APweb. (2021). Angiosperm phylogeny website. http://www.mobot.org/MOBOT/research/APweb/.

Araújo, A. A. M. (2013). Aristolochiaceae Juss. na Mata Atlântica do nordeste, Brasil. Dissertação de Mestrado, Universidade Federal do Pernambuco, Recife, PE, Brasil.

Araújo, C. F. (2017). Morfodiagnose macroscópica, comparação anatômica, histoquímica e fitoquímica de Aristolochia labiata Willd, Aristolochia odoratissima L. e Aristolochia silvatica Barb. Rodr.: espécies medicinais da Amazônia Meridional. Dissertação de Mestrado, Universidade do Estado de Mato Grosso, Alta Floresta, MT, Brasil.

BFG (2015). Growing knowledge: an overview of Seed Plant diversity in Brazil. Rodriguésia, 66 (4), 1085-1113.

Barreto, M. R. \& Spanholi, M. L. (2019). Estudo etnobotânico em comunidades rurais de Sinop, Mato Grosso, Brasil. Interações, 20, 267-282. Doi.org/10.20435/inter.v20i1.1889

Barroso, G. M., Morim, M. P., Peixoto, A. L., Ichasso \& C. L. F. (1999). Frutos e sementes: morfologia aplicada a sistemática de dicotiledôneas. Editora UFV.

Borges, H. B. N., Silveira, E. A. \& Vendramin, L. N. (2014). Flora arbórea de Mato Grosso: tipologias vegetais e suas espécies. Cuiabá: Entrelinhas.

Capellari-Júnior, L. (1991). Espécies de Aristolochia L. (Aristolochiaceae) ocorrentes no estado de São Paulo. Dissertação de Mestrado, Campinas, SP, Brasil.

Capellari-Júnior, L. (2002). Aristolochiaceae. In: Wanderley, M. G. L., Shepherd, G. J., Giulietti, A. M., Melhem, T. S., Bittrich, V., \& Kameyama, C. (eds.). Flora Fanerogâmica do Estado de São Paulo Online. 2. RiMa, 299-308.

Capellari-Júnior, L. (2005). Potencial ornamental das aristoloquiáceas. Revista Brasileira de Horticultura Ornamental 11(2): 82-88.

Dubs, B. (1998). Prodromus Florae Matogrossensis - Part I - Checklist of Angiosperm. Küsnacht: Betrona-Verlag.

Fernandes, J. M., Soares-Lopes, C. R. A., Ribeiro, R. S. Silva, D. R. (2015). Leguminosae no acervo do Herbário da Amazônia Meridional, Alta Floresta, Mato Grosso. Enciclopédia Biosfera, 11 (21), 2272-2293.

Fidalgo, O. \& Bononi, V. L. R. (1989). Técnicas de coleta, preservação e herborização do material botânico. Instituto de Botânica.

Flora do Brasil (2020). Flora do Brasil 2020 - Algas, Fungos e Plantas. Jardim Botânico do Rio de Janeiro. http://floradobrasil.jbrj.gov.br/.

Freitas, J. \& Alves-Araújo, A. (2017). Flora do Espírito Santo: Aristolochiaceae. Rodriguésia, 68 (5), 1505-1539. 10.1590/2175-7860201768501

Freitas, J., Lirio, E. J., Barros, F. \& González, F. 2020. Aristolochiaceae in Flora do Brasil 2020. Jardim Botânico do Rio de Janeiro. http://floradobrasil.jbrj.gov.br/reflora/floradobrasil/FB15749.

González, F. (1990). Flora de Colombia: Aristolochiaceae. Monografia nº 12. Bogotá: Universidad Nacional de Colombia - Instituto de Ciencias Naturales.

González, F. (1991). Notes on the systematics of Aristolochia subsect. Hexandrae. Annals Missouri Botanical Garden, 78 (2), 497-503. Doi.org/10.2307/2399576

González, F. (2000). A new species of Aristolochia (Aristolochiaceae) from Bahia, Brazil. Novon, 10, 371-374. Doi.org/10.2307/3392989

González, F. \& Pabón-Mora, N. (2017). Aristolochia keratuma (Aristolochiaceae), nueva especie de Aristolochia serie Thyrsicae del Chocó (Colombia) y clave de identificación para sus especies. Caldasia, 39 (1), 50-58. Doi.org/10.15446/caldasia.v39n1.63168

Hoehne, F. C. (1927). Monographia illustrada das aristolochiaceas brasileiras. Memórias do Instituto Oswaldo Cruz, $20,67-175$.

Hoehne, F.C. (1942). Aristolochiaceas. Flora Brasílica 15: 1-141, t. 1-123. Instituto de Botânica. 
IBGE (2012). Manual técnico da vegetação brasileira: sistema fitogeográfico, inventário das formações florestais e campestres, técnicas e manejo de coleções botânicas, procedimentos para mapeamentos. Rio de Janeiro: IBGE.

IBGE (2017). Divisão regional do Brasil em regiões geográficas imediatas e regiões geográficas intermediárias. https://biblioteca.ibge.gov.br/visualizacao/livros/liv100600.pdf.

INPE (2020). A taxa consolidada de desmatamento por corte raso para os nove estados da Amazônia Legal (AC, AM, AP, MA, MT, PA, RO, RR e TO) em 2019 é de $10.129 \mathrm{~km}^{2}$. http://www.inpe.br/noticias/noticia.php?Cod_Noticia=5465.

Larocca, D. G. (2016). Estudos botânicos de espécies medicinais utilizadas no tratamento de malária e dengue. Dissertação de Mestrado, Universidade do Estado de Mato Grosso, Alta Floresta, MT, Brasil.

Lopes, C. R. A. S. (2015). Herbário da Amazônia Meridional, Mato Grosso (HERBAM). Bioscience, Edição Especial, 4 (6), $36-39$.

Lopes-Soares, C. R. A., Ribeiro, I. L., Silva, D. R., Verão, D.S., Santos, R. C., Oliveira, O. F., Batista, A. P. M. \& Ribeiro, R. S. (2013). Contribuição do acervo do HERBAM à flora de angiospermas da Amazônia Mato-grossense. In $64^{\circ}$ Congresso Nacional de Botânica. Belo Horizonte, $10-15$ de Novembro de 2013. http://www.botanica.org.br/trabalhos-cientificos/64CNBot/resumo-ins20226-id5388.pdf

Lorenzi, H. \& Abreu-Matos, F. J. (2008). Plantas medicinais no Brasil: nativas e exóticas (2 ed.).: Instituto Plantarum de Estudos da Flora.

Martinelli, G., Valente, A. S. M., Maurenza, D., Kutschenko, D. C., Judice, D. M., Silva, D. S., Fernandez, E. P., Martins, E. M., Barros, F. S. M., Sfair, J. C., Santos-Filho, L. A. F., Abreu, M. B., Moraes, M. A., Monteiro, N. P., Pietro, P. V., Fernandes, R. A., Hering, R. L. O., Messina, T. \& Penedo, T. S. A. (2013). Avaliações de risco de extinção de espécies da flora brasileira. In: Martinelli, G. \& Moraes, M. A. Livro vermelho da flora do Brasil. Rio de Janeiro: Andrea Jakobsson Editora e Instituto de Pesquisas Jardim Botânico do Rio de Janeiro, Pp. 60-103.

Mato Grosso (2015). Economia. http://www.mt.gov.br/economia.

Muñoz-Gómez, S., Suárez-Baron, H., Alzate, J. F., González, F. \& Pabón-Mora, N. (2021). Evolution of the subgroup 6 R2R3-MYB genes and their contribution to floral color in the perianth-bearing Piperales. Frontiers in Plant Science, 12, 633227.

Nascimento, D. S. (2008). Estudo taxonômico da família Aristolochiaceae Juss. do Sul do Brasil. Dissertação de Mestrado. Universidade Federal do Paraná. $123 \mathrm{p}$.

Pabón-Mora, N., Suarez-Baron, H., González, F. \& Ambrose, B. A. (2015). Flower development and perianth identity candidate genes in the basal angiosperm Aristolochia fimbriata (Aristolochiaceae). Frontiers in Plant Science, 6, 1095. 10.3389/fpls.2015.01095

Pauli, P. T., Rios, R. S., Bieski, I. G. C. \& Silva, J. S. (2018). Estudo etnobotânico de plantas medicinais em bairros de Juína, Mato Grosso, Brasil. Revista Saúde Viva Multidisciplinar da AJES, 1, 117-156.

Peréz-Mesa, P., Suárez-Baron, H., Ambrose, B. A., González, F. \& Pabón-Mora, N. (2019). Floral MADS-box protein interactions in the early diverging angiosperm Aristolochia fimbriata Cham. (Aristolochiaceae: Piperales). Evolution and Development, 21, 96-110.

Radford, A. E., Dickison, W. C., Massey, J. R. \& Bell, C. R. (1974). Vascular plant systematics.: Harper \& Row.

SEPLAN (2017). Regiões de planejamento de Mato Grosso. Cuiabá: Secretaria de Estado de Planejamento.

Souza, V. V., Spadeto, M. S., Guedes, R. A., Clarindo, W. R., Carvalho, C. R., Severi, J. A. \& Souza, T. S. (2020). Toxicity of Aristolochia decoction: a relevant herbal in folk medicine. International Journal of Cytology Cytosystematics and Cytogenetics, 73 (3), 111-120. Doi.org/10.13128/caryologia-880

Suárez-Baron, H., Perez-Mesa, P., Ambrose, B., González, F., Pabón-Mora, N. (2016). Deep into de Aristolochia Flower: expression of C, D and E class genes in Aristolochia fimbriata (Aristolochiaceae). Journal of Experimental Zoology part B, 328, 55-71. Doi.org/10.1002/jez.b.22686

Suárez-Baron, H., Alzate, J. F., González, F., Ambrose, B. A., Pabón-Mora, N. (2019). Genetic mechanisms underlying perianth epidermal elaboration of Aristolochia ringens Vahl (Aristolochiaceae). Flora, 253, 56-66.

Suárez-Baron H., Alzate J.F., González F., Pelaz S., Ambrose B.A. \& Pabón-Mora N. (2021). Gene expression underlying floral epidermal specialization in Aristolochia fimbriata (Aristolochiaceae). Annals of Botany, 127, 749-764.

Ulloa-Ulloa, C., Acevedo-Rodríguez, P., Beck, S., Belgrano, M. J., Bernal, R., Berry, P. E., Brako, L., Celis, M., Davidse, G., Forzza, R. C., Gradstein, S. R., Hokche, O., Léon, B., León-Yánez, S., Magill, R. E., Neill, D. A., Nee, M., Raven, P. H., Stimmel, H., Strong, M. T., Villaseñor, J. L., Zarucchi, J. L., Zuloaga, F. O. \& Jørgensen, P. M. (2017) An integrated assessment of the vascular plant species of the Americas. Science, 358, 1614-1617. Doi.org/10.1126/science.aao0398. 